\title{
Get on the (curbside) bus: The new intercity bus
}

\author{
Nicholas J. Klein ${ }^{\text {a }}$ \\ Rutgers, the State University of New Jersey
}

\begin{abstract}
Curbside buses are intercity buses that pick up and drop off on city streets and corners instead of bus terminals. These new buses have only been operating for 15 years but have quickly revitalized and transformed the intercity bus industry, leading to the first increases in ridership in 50 years. Using a passenger intercept survey of both curbside and established carriers, such as Greyhound, I address two basic questions about this new mode: Who uses curbside buses? And what is the effect of curbside buses on competing modes? The findings indicate that curbside buses appear to be attracting different passengers than established carriers. After using curbside buses, passengers are less likely to use Amtrak for intercity trips, but the buses have no effect on their likelihood to drive.
\end{abstract}

\section{Introduction}

After many years of declining operations, ridership, and finances, the intercity bus industry in the United States is experiencing resurgence. This revival is rooted in a new sector of the bus industry, the curbside carrier. These new entrants to the market—such as Megabus, BoltBus, and the so-called "Chinatown buses"-are offering lower prices, innovative services, and higher frequencies (Klein 2009). Ridership is up, and services are expanding throughout the United States (Schwieterman et al. 2013; Schwieterman et al. 2007).

Yet we know little about who is riding these buses or how these new services are changing travel behavior. This article uses an intercept survey and focus groups with intercity bus passengers to begin to understand how these new entrants alter the market for intercity bus travel. I use the intercept survey to examine the demographic composition of the different sectors in the bus industry. I make use of both the survey and the focus groups to get a sense of how these curbside buses may be changing travel behavior. If the new entrants to the market attract passengers who otherwise would have driven, then the net environmental impact of these buses is likely positive. However, if most riders switch from possibly more energy-efficient trains to buses, then the net environmental impact could be negative. Similarly, if curbside buses draw a large number of passengers away from rail or air travel, then this shift could have important financial consequences for public investment in high-speed rail and airport expansion.

The intercity bus industry is rapidly changing; the survey and focus groups used here represent the state of the curbside bus industry at a particular time. At the time of this survey, during the second half of 2010, many Chinatown bus companies were thriving on the Northeast Corridor. Subsequently, almost all were shut down (U.S. Department of Transportation 2013). More recently, several new Chinatown buses have begun operating, and others have resumed operations (Arino 2014).

This article begins with an overview of the intercity bus industry. The following section describes the long decline and more recent revival of the industry, then describes the survey and focus groups.

anick.klein@rutgers.edu

Copyright 2015 Nicholas J. Klein

http://dx.doi.org/10.5198/jtlu.2015.419

ISSN: 1938-7849 | Licensed under the Creative Commons Attribution - NonCommercial License 3.0.

The Journal of Transport and Land Use is the official journal of the World Society for Transport and Land Use (WSTLUR) and is published and sponsored by the University of Minnesota Center for Transportation Studies. 
Next, it analyzes the demographics of intercity bus ridership and models how respondents' travel behavior may be changing. Finally, it concludes with a discussion of the findings.

\section{The curbside bus industry}

The contemporary intercity bus industry includes several types of bus service. In this paper, I focus on legacy carriers and two types of curbside intercity bus companies. Legacy intercity bus companies are those companies that existed prior to deregulation, such as Greyhound Bus Lines and Peter Pan. These carriers continue to stage most of their operations out of bus terminals, though they are increasingly adopting business practices pioneered by curbside carriers.

Curbside carriers are the new entrants into the marketplace. By and large, these companies pick up and drop off passengers on city streets rather than in bus terminals. One type, the so-called "Chinatown buses, 1" were the first curbside carriers to appear on the scene in the late 1990s. These companies initially served an exclusively co-ethnic population but quickly attracted other passengers. Within 10 years, there were 10 to 15 companies offering service between urban Chinese-immigrant enclaves in more than 25 cities, though the connections from New York to Boston, Philadelphia, and Washington, DC, were the most significant routes (Klein 2009). Though there are variations among the companies, the Chinatown buses generally use flat fares (prices that do not vary by time or occupancy) and sell most tickets online, via cash transactions on the bus itself, on the street, or in small storefronts.

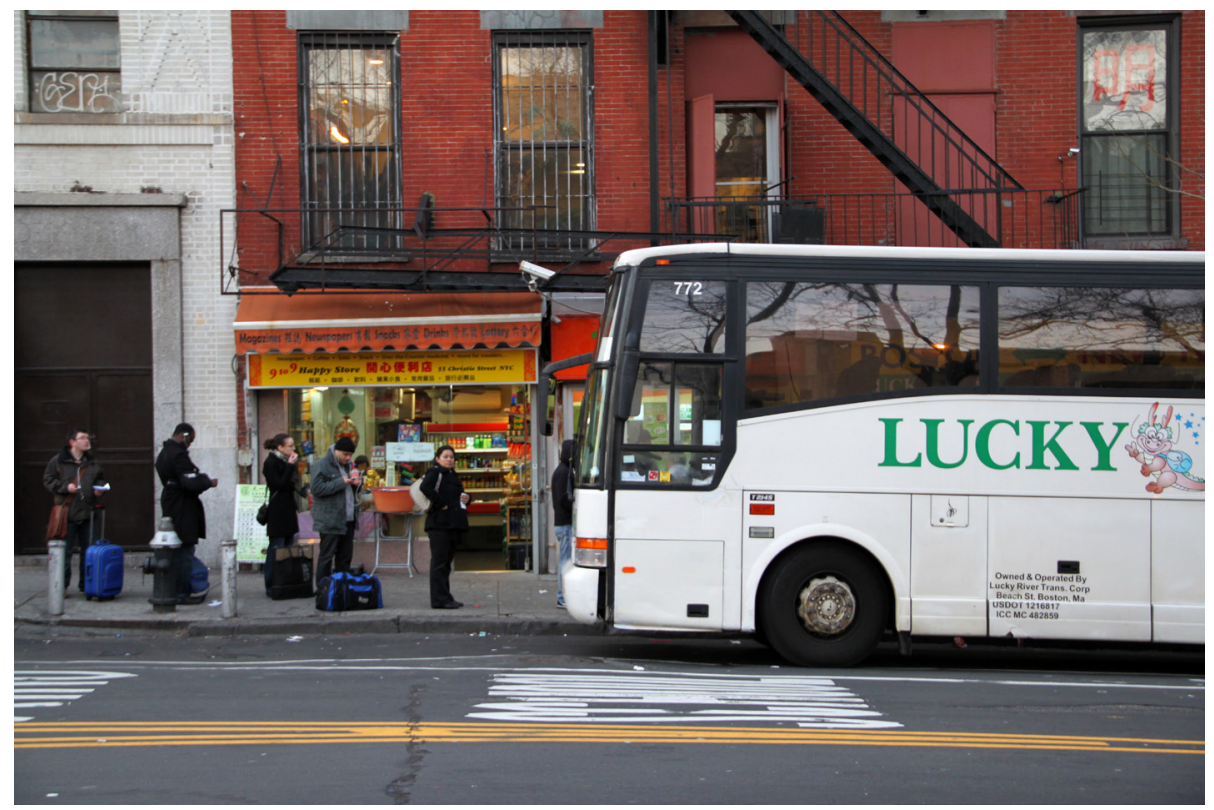

Figure 1: Chinatown bus, New York City (Source: Travis Eby 2012).

Second are the corporate curbside buses owned by large multinational corporations. This sector includes BoltBus (which is jointly owned by Greyhound, a subsidiary of FirstGroup, and Peter Pan) and Megabus (owned by Stagecoach Corporation). Megabus first began operating in the United Kingdom in 2004 and opened a hub in the United States in Chicago in 2006. In 2008, Megabus and BoltBus began operating intercity bus service on the Northeast Corridor (Klein 2009).

Corporate curbside operators primarily stage their operations in central business districts and use new buses with distinctive branding. The buses feature onboard wireless Internet and power outlets for personal electronics. The companies rely on online ticket sales and set fares via yield management algorithms, which offer low prices for the first few tickets sold on each departure and higher fares for 
subsequent tickets. The fares can be as low as $\$ 1$ (plus transaction fees), though the fares quickly rise and are often comparable to the fares on the Chinatown buses (e.g., $\$ 20$ for a trip from New York to Washington, DC).

In the past few years, corporate curbside buses have expanded throughout the United States and into Canada. BoltBus has expanded service beyond the Northeast to both the Pacific Northwest and California (BoltBus 2013). Megabus now serves more than 100 cities in North America with hubs in Chicago, New York, Philadelphia, Pittsburgh, Toronto, Washington, DC, Atlanta, Dallas, and San Francisco (Megabus 2013).

I exclude intercity bus services that have not attracted a diverse ridership and have little short-term potential to affect travel behavior (e.g., camionetas and similar bus companies that exclusively serve a coethnic immigrant ridership base) and casino, tour, charter, and airport buses because they only provide service to specialized destinations.

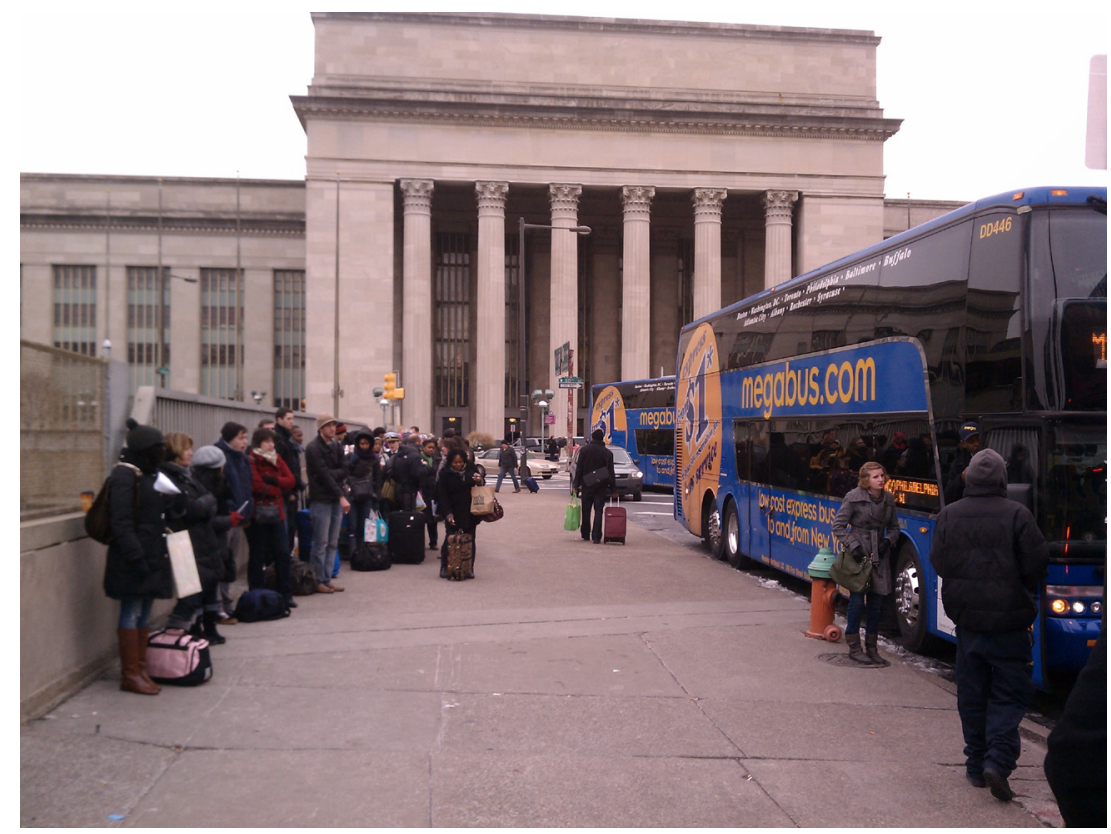

Figure 2: Megabus, Philadelphia (Source: Author 2012).

\section{The decline and rise of intercity buses in the United States}

During the second half of the 20th century, the intercity bus industry in the United States experienced a long, slow decline. Intercity bus use declined from a mode share of roughly 10 percent of all intercity trips at the end of World War II to 2.5 percent in the 1960s (Meyer et al. 1987). Between 1960 and 2002, the number of intercity bus departures decreased by a further 60 percent (Fischer and Schwieterman 2011). As Americans with the means took to the air or drove, many travelers came to view intercity buses as a mode of last resort (Meyer et al. 1987; Walsh 2000). Ridership on intercity buses was disproportionately comprised of the young, the old, females, minorities, and the poor (Meyer et al. 1987; Bricka 2001; U.S. Department of Transportation 1998). Though the federal government deregulated the intercity bus industry in the early 1980s, the perception of intercity buses, the economic position of bus companies, and ridership all continued to decline (Berechman 1993).

Curbside buses upended the market for intercity bus travel, particularly on the Northeast Corridor. From 1998 to 2007, the number of intercity bus passengers on the Northeast Corridor (between Boston and Washington, DC) doubled to more than seven million annual passengers (Greyhound Bus 
Lines 2007). For the first time since 1960, scheduled intercity bus service increased in the United States (Schwieterman et al. 2007). The curbside industry continues to change this pattern. Megabus and BoltBus have almost doubled their departures between 2010 and 2012 (Schwieterman et al. 2013).

However, research on the new intercity bus industry is limited. Large-scale travel surveys, such as the 2001 and 2009 National Household Travel Surveys, record too few intercity bus trips to be useful in examining changing intercity bus ridership. The most recent national survey of long-distance travel was in 1995, prior to the era of curbside buses. Much of the existing research has focused on documenting the growth of the industry (e.g. Klein 2009; Schwieterman et al. 2013; Schwieterman et al. 2011; Schwieterman et al. 2007). Klein and Zitcer (2012) examined the experiential and cultural dimensions of the Chinatown buses, in particular the way that many passengers use travel on these buses as a way to experience the "other," and they frame riding these buses as an authentic urban experience.

The few studies of intercity bus passengers suggest that the new entrants to the marketplace could be changing the demographics of intercity bus travel. Schwieterman and Fischer (2012) recently surveyed more than 1000 passengers boarding buses in the Midwest and in the Northeast, finding that curbside buses are generating significant amounts of new travel, that roughly one-third of curbside bus passengers would have used rail if the curbside bus were unavailable, and that three-quarters of curbside bus passengers are 18 to 35 years old. While providing some basic information, the study only offers a limited demographic profile of curbside bus users (only age and gender are reported) and excludes passengers on the Chinatown buses. Similarly, a small survey (100 respondents) of curbside bus ridership in the United Kingdom found that, compared with passengers on the established carrier (National Express), Megabus passengers are younger, more likely to be students, and less likely to own a car (White and Robbins 2012).

The intercity bus industry has rapidly grown in the past 15 years, but little is known about who is riding these buses and how they are changing intercity travel. This article draws on a passenger intercept survey and a series of focus groups with intercity bus passengers to understand these changes in the Northeast region.

\section{$4 \quad$ Passenger survey and focus groups}

Table 1: Survey distribution.

\begin{tabular}{|l|c|c|c|c|}
\hline & New York & Philadelphia & Total & Percent \\
\hline Chinatown bus & 4 & 227 & 231 & $30.0 \%$ \\
\hline Corporate curbside bus & 99 & 226 & 325 & $42.2 \%$ \\
\hline Legacy bus & 0 & 215 & 214 & $27.8 \%$ \\
\hline Total & 103 & 668 & 770 & \\
\hline
\end{tabular}

In summer 2010, I surveyed intercity bus passengers about their intercity travel in the Northeast and their basic demographic information (see appendix). With the help of several research assistants, we administered a brief survey to passengers waiting to board intercity buses in New York and Philadelphia.

We collected 770 valid responses. Of those, 86 percent (667) were collected in Philadelphia (see Table 1). We collected more surveys in Philadelphia for several reasons: Bus stops in Philadelphia were more centralized; we had access to the Greyhound bus terminal in Philadelphia; and one of the research assistants collecting surveys in Philadelphia was a native Mandarin speaker, which may have helped increase the response rate in Philadelphia. In Philadelphia, research assistants estimated that the refusal rates were roughly 10 percent for corporate curbside bus passengers, 20 percent for legacy buses, and 25 percent for Chinatown bus passengers. The corporate curbside bus surveys were split among BoltBus 
(44 percent) and MegaBus (56 percent). The surveys of legacy bus passengers were collected in the waiting area of the Greyhound bus terminal and did not ask about the bus operator, but it is most likely these passengers were boarding Greyhound buses.

In addition to the survey, I held five focus groups with curbside bus passengers in Philadelphia and New York between August and October 2009, including one focus group that was conducted in Mandarin (for more on the focus groups, see Klein and Zitcer 2012; Klein 2014). I moderated the English language focus groups and recruited participants at intercity bus stops in Philadelphia and New York. For the Mandarin language focus group, I hired a native Mandarin-speaking graduate student to conduct the focus group and used the same focus group protocol. The 37 focus group participants were, on average, 31 years old (ranging from 20 to 58), with 18 men and 19 women. Almost half of the participants were employed full-time and almost one-quarter of the participants were students.

There are several limitations to this data collection. The intercity bus industry is rapidly changing, and as a result, the survey analyzed here, fielded in 2010, may be out of date. Further, I only collected surveys in New York and Philadelphia; the populations and experiences of bus passengers in other parts of the country could be different. I only collected a small number of Chinese language survey responses (19) and conducted only one Mandarin language focus group and thus underrepresent Chinese language speakers. My data collection excludes travelers who choose not to take intercity buses (such as travelers who tried curbside buses but then continued to use other modes). Finally, I do not know whether refusals were more common among particular population groups.

\section{$5 \quad$ Findings}

Curbside buses are changing intercity travel in the United States. These new buses are attracting different riders than legacy bus companies, and these bus companies are changing travel habits.

The following analysis classifies survey respondents as Chinatown bus passengers, corporate curbside bus passengers, or legacy bus passengers based on the type of bus they were boarding. For example, I classified respondents surveyed prior to boarding a Chinatown bus as "Chinatown bus passengers." Table 2 summarizes the share of all trips and intercity bus trips made on the mode where the survey was collected.

Table 2: Share of trips made on bus where survey was administered.

\begin{tabular}{|l|c|c|}
\hline & Share of all trips made on this bus & Share of all bus trips made on this bus \\
\hline All recipients & $58 \%$ & $81 \%$ \\
\hline Chinatown bus & $65 \%$ & $83 \%$ \\
\hline Corporate curbside bus & $58 \%$ & $83 \%$ \\
\hline Legacy bus & $49 \%$ & $74 \%$ \\
\hline
\end{tabular}

\subsection{Who rides curbside buses?}

The Chinatown and corporate curbside buses attract passengers who are markedly different from legacy bus passengers across age, sex, income, and race and ethnicity (Table 3). Passengers boarding the Chinatown bus were younger than those boarding legacy buses and a larger share of the Chinatown bus passengers were male compared with passengers on either corporate curbside or legacy buses. The lower share of female passengers boarding the Chinatown bus could be an artefact of the higher nonresponse among Chinatown bus passengers. Alternatively, some aspect of these buses could make women feel less comfortable using them. In the focus groups, some women did report avoiding the Chinatown bus at 
night out of concerns for their safety at the bus stop. And the lower share of female passengers could also be due to a potentially higher rate of refusals among women to complete the survey.

The survey data also show that a higher proportion of the Chinatown bus respondents were Asian (26 percent), compared with 14 percent on corporate curbside buses and 8 percent on legacy buses. However, white passengers made up the largest race/ethnic group on all the buses (37 percent on Chinatown buses). Fewer Chinatown bus passengers were working full-time (41 percent) and more were employed part-time (18 percent), compared with legacy buses (51 percent employed full-time and 10 percent employed part-time). These rates of full- and part-time employment were the same for passengers on the Chinatown and corporate curbside buses. Other demographic differences were not statistically significant.

Table 3: Intercity bus passenger demographics.

\begin{tabular}{|c|c|c|c|c|c|c|}
\hline & \multirow{2}{*}{$\frac{\text { Corp. Curbside Bus }}{\text { A }}$} & \multirow{2}{*}{$\frac{\text { Chinatown Bus }}{\text { B }}$} & \multirow{2}{*}{$\frac{\text { Legacy Bus }}{\text { C }}$} & \multicolumn{3}{|c|}{ T-tests or pr-test sig. } \\
\hline & & & & A vs. B & A vs. $\mathrm{C}$ & B vs. C \\
\hline Count & 325 & 231 & 214 & & & \\
\hline Survey in English (\%) & $100 \%$ & $92 \%$ & $100 \%$ & $\mathrm{p}<0.01$ & n.s. & $\mathrm{p}<0.01$ \\
\hline Gender ( $\%$ female) & $56 \%$ & $46 \%$ & $59 \%$ & $\mathrm{p}<0.05$ & n.s. & $\mathrm{p}<0.01$ \\
\hline \multicolumn{7}{|l|}{ Household income (\%) } \\
\hline Less than $\$ 40,000$ & $40 \%$ & $46 \%$ & $42 \%$ & n.s. & n.s. & n.s. \\
\hline$\$ 40,001$ to $\$ 80,000$ & $30 \%$ & $36 \%$ & $37 \%$ & n.s. & $\mathrm{p}<0.10$ & n.s. \\
\hline Greater than $\$ 80,000$ & $31 \%$ & $18 \%$ & $20 \%$ & $\mathrm{p}<0.01$ & $\mathrm{p}<0.05$ & n.s. \\
\hline Household size (median) & 2.8 & 3.0 & 2.8 & n.s. & n.s. & n.s. \\
\hline Has access to auto (\%) & $47 \%$ & $42 \%$ & $46 \%$ & n.s. & n.s. & n.s. \\
\hline Auto owner (\%) & $66 \%$ & $64 \%$ & $66 \%$ & n.s. & n.s. & n.s. \\
\hline Age (mean) & 29.4 & 27.8 & 30.3 & n.s. & n.s. & $\mathrm{p}<0.05$ \\
\hline 18 to 35 years old & $75 \%$ & $79 \%$ & $68 \%$ & n.s. & n.s. & $\mathrm{p}<0.01$ \\
\hline 36 to 50 years old & $14 \%$ & $12 \%$ & $16 \%$ & n.s. & n.s. & n.s. \\
\hline 51 to 65 years old & $8 \%$ & $5 \%$ & $8 \%$ & n.s. & n.s. & $\mathrm{p}<0.10$ \\
\hline Over 65 years old & $3 \%$ & $4 \%$ & $8 \%$ & n.s. & $\mathrm{p}<0.10$ & $\mathrm{p}<0.10$ \\
\hline \multicolumn{7}{|l|}{ Race/ethnicity (\%) } \\
\hline African American/Black & $12 \%$ & $25 \%$ & $30 \%$ & $\mathrm{p}<0.01$ & $\mathrm{p}<0.01$ & n.s. \\
\hline Asian (API) & $14 \%$ & $26 \%$ & $8 \%$ & $\mathrm{p}<0.01$ & $\mathrm{p}<0.05$ & $\mathrm{p}<0.01$ \\
\hline Hispanic & $7 \%$ & $8 \%$ & $14 \%$ & n.s. & $\mathrm{p}<0.10$ & n.s. \\
\hline White & $60 \%$ & $37 \%$ & $41 \%$ & $\mathrm{p}<0.01$ & $\mathrm{p}<0.01$ & n.s. \\
\hline Other & $2 \%$ & $4 \%$ & $6 \%$ & n.s. & $\mathrm{p}<0.10$ & n.s. \\
\hline Multiple race & $5 \%$ & $1 \%$ & $1 \%$ & $\mathrm{p}<0.05$ & $\mathrm{p}<0.05$ & n.s. \\
\hline \multicolumn{7}{|l|}{ Employment status (\%) } \\
\hline Working full-time & $41 \%$ & $41 \%$ & $51 \%$ & n.s. & $\mathrm{p}<0.10$ & $\mathrm{p}<0.05$ \\
\hline Working part-time & $18 \%$ & $18 \%$ & $10 \%$ & n.s. & $\mathrm{p}<0.10$ & $\mathrm{p}<0.05$ \\
\hline Student & $19 \%$ & $20 \%$ & $20 \%$ & n.s. & n.s. & n.s. \\
\hline Not working & $13 \%$ & $13 \%$ & $14 \%$ & n.s. & n.s. & n.s. \\
\hline Other & $8 \%$ & $8 \%$ & $5 \%$ & n.s. & n.s. & n.s. \\
\hline
\end{tabular}


Corporate curbside bus passengers form another distinct group of intercity bus passengers. The most striking attribute of this group is the proportion of passengers reporting household incomes greater than $\$ 80,000$ per year (31 percent), compared with 18 and 20 percent on the Chinatown and legacy buses, respectively. Additionally, higher shares of corporate curbside passengers are white (60 percent) or Asian (14 percent), compared to legacy bus passengers (41 percent white and 8 percent Asian). The survey did not distinguish between US-born and foreign-born persons; it is possible that the Chinatown bus attracts more foreign-born passengers than the corporate curbside bus, as research on immigrantoriented bus operators has shown (Valenzuela et al. 2005). Fewer corporate curbside bus passengers are black (12 percent), compared with 25 percent of Chinatown bus passengers and 30 percent of legacy bus passengers. Other differences were not statistically significant.

Survey respondents for all bus types were very young, and those on the Chinatown buses were the youngest. This is different from surveys of intercity bus passengers taken before the era of curbside buses, which consistently noted large shares of older intercity bus passengers (Meyer et al. 1987; Bricka 2001; U.S. Department of Transportation 1998). This survey was conducted during the summer and could underestimate the proportion of young passengers given that corporate curbside bus companies often locate their stations near colleges and universities to attract student passengers (White and Robbins 2012)

For all respondents, the primary purpose for most intercity trips was visiting friends or relatives, followed by vacation trips (Table 4). Passengers boarding the Chinatown buses were more likely to report traveling for work-related purposes, compared with those boarding other buses.

Travelers are also traveling to the buses from neighborhoods. Seventy-five percent of the respondents (550) provided a valid ZIP code in their survey. The largest number of respondents' ZIP codes were in Philadelphia (194) followed by New York (147). Figure 3 maps the distribution of residential locations of passengers living in Philadelphia by bus type. The locations for the staging operations are indicated with a yellow dot for legacy buses, blue for corporate curbside buses, and red for the Chinatown buses (all within one mile of each other, and well served by public transit). The map of residences by ZIP code includes 80 Chinatown bus respondents, 73 corporate curbside respondents, and 41 legacy bus respondents.

The maps show that the different bus types appear to draw passengers from different areas in Philadelphia. Corporate curbside bus passengers live closer to corporate bus staging areas in Philadelphia, with the highest concentration in West Philadelphia near the University of Pennsylvania and Drexel University. Survey respondents boarding the corporate curbside bus lived on average 4 kilometers $(2.5$ miles) from the corporate curbside bus stop, compared with 5.8 kilometers (3.6 miles) for passengers

Table 4: Trip purpose (more than one reason allowed).

\begin{tabular}{|r|c|c|c|c|c|c|}
\hline & Corp. Curbside Bus & Chinatown Bus & Legacy Bus & \multicolumn{3}{|c|}{ T-tests } \\
\cline { 2 - 7 } & $\mathrm{A}$ & $\mathrm{B}$ & $\mathrm{C}$ & $\mathrm{A}$ vs. B & A vs. C & B vs. C \\
\hline Visit friends or relatives & $46 \%$ & $42 \%$ & $48 \%$ & n.s. & n.s. & n.s. \\
\hline Vacation & $20 \%$ & $18 \%$ & $20 \%$ & n.s. & n.s. & n.s. \\
\hline Business & $14 \%$ & $15 \%$ & $6 \%$ & n.s. & $\mathrm{p}<0.01$ & $\mathrm{p}<0.01$ \\
\hline Entertainment & $10 \%$ & $11 \%$ & $12 \%$ & n.s. & n.s. & n.s. \\
\hline Shopping & $2 \%$ & $5 \%$ & $7 \%$ & $\mathrm{p}<0.05$ & n.s. & n.s. \\
\hline To or from work & $2 \%$ & $5 \%$ & $2 \%$ & n.s. & n.s. & $\mathrm{p}<0.1$ \\
\hline School-related activity & $3 \%$ & $3 \%$ & $2 \%$ & n.s. & n.s. & n.s. \\
\hline Other & $3 \%$ & $2 \%$ & $3 \%$ & n.s. & n.s. & n.s. \\
\hline $\mathrm{N}$ & 377 & 263 & 203 & & & \\
\hline
\end{tabular}


boarding both Chinatown and legacy buses. (The difference in distances between corporate curbside buses and the other bus types is significant.) Passengers boarding legacy and Chinatown buses were more distributed throughout the city, with many residents living in Center City, West and southwest Philadelphia, and North Philadelphia.

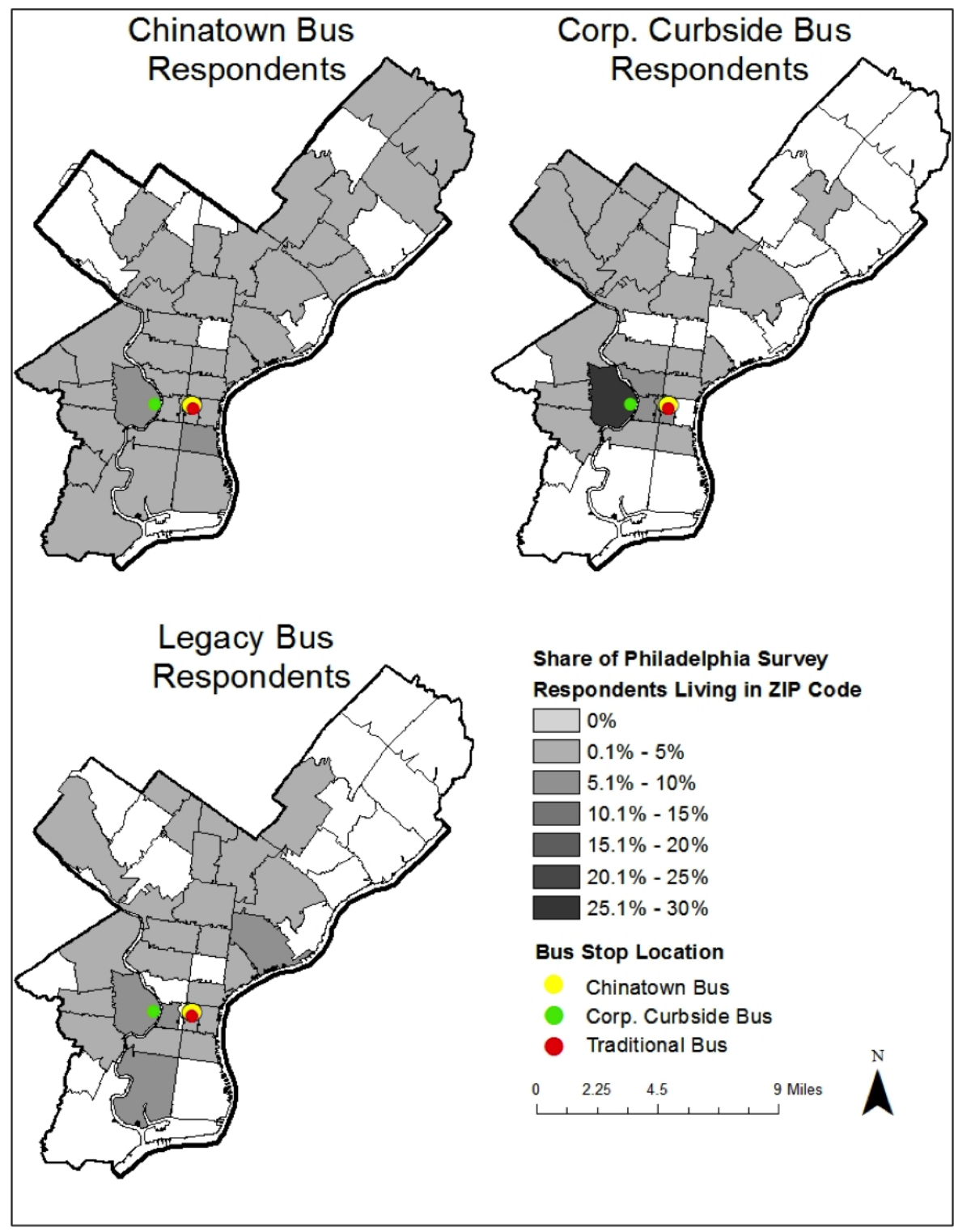

Figure 3: Distribution of residences in Philadelphia.

\subsection{Changing intercity travel behavior}

Given that curbside bus ridership is growing, are other modes suffering at the expense of the curbside bus boom? To assess the potential changes in mode choice, I asked survey respondents whether they were more or less likely to use Amtrak or drive2 since they started traveling by curbside bus, and then I compared these responses with those for legacy bus passengers. (For these respondents, I asked about 
their use of other intercity modes since they started using legacy buses.)

The following presents an analysis of the participants' reported changes in their likelihood to use Amtrak and likelihood to drive. ${ }^{3}$ For each of the changes in behavior, I first summarize participants' survey responses and then use an ordered logit model to control for various factors possibly correlated with the respondents' likelihood to use various modes. ${ }^{4}$ The dependent variable in the ordered logit model is the likelihood to drive or use Amtrak (1 to 5, from least to most likely). The independent variables include the key variables of interest, indicating whether the respondent was on a curbside bus (either corporate or a Chinatown bus), where the reference category is legacy bus. The model also includes the respondent's age, sex, race', ethnicity, household size, household income, whether the respondent lives in New York City or Philadelphia, auto ownership, and a dummy variable, indicating whether the survey respondent reported that he or she could have easily made this trip by automobile.

\section{Less Amtrak use after riding curbside buses}

Curbside bus respondents are much less likely to use Amtrak compared with passengers using legacy carriers. Figure 4 graphs responses to the survey question about respondents' likelihood to use Amtrak after taking a corporate curbside bus, Chinatown bus, or legacy bus. More corporate curbside bus and Chinatown bus passengers indicated that they were "much less likely" or "less likely" to use Amtrak, compared with legacy bus passengers. However, just over half (51 percent) of Chinatown bus passengers reported "no change" in their likelihood to use Amtrak after using a Chinatown bus, suggesting many of these passengers may not view the two modes as substitutes for each other. And the share of legacy bus passengers who were "more likely" or "much more likely" to use Amtrak after using a legacy bus was much higher than for the curbside bus modes, indicating that perhaps legacy bus passengers were not satisfied with these buses.

\begin{tabular}{|c|c|c|c|c|c|c|}
\hline & $\begin{array}{c}\text { Much } \\
\text { Less likely }\end{array}$ & $\begin{array}{l}\text { Less } \\
\text { likely }\end{array}$ & $\begin{array}{c}\text { No } \\
\text { change }\end{array}$ & $\begin{array}{l}\text { Mor } \\
\text { likel }\end{array}$ & & $\begin{array}{c}\text { Much } \\
\text { More likely }\end{array}$ \\
\hline $\begin{array}{c}\text { Chinatown } \\
\text { bus }\end{array}$ & $15 \%$ & $20 \%$ & $51 \%$ & & $3 \%$ & \\
\hline Corp. bus & $19 \%$ & $25 \%$ & $34 \%$ & $15 \%$ & $7 \%$ & \\
\hline Legacy bus & & $14 \%$ & $32 \%$ & $25^{\circ}$ & & $14 \%$ \\
\hline
\end{tabular}

Figure 4: Likelihood to use Amtrak since it started using curbside or legacy buses.

The ordered logit model also suggests that, compared with legacy bus passengers, survey respondents who use corporate curbside buses and Chinatown buses are significantly less likely to use Amtrak since they began using corporate curbside buses and Chinatown buses, even after controlling for age, sex, income, race, ethnicity, and auto availability. Table 4 summarizes the incident risk ratio for each model coefficient along with the p-value. Model 1 includes only the variable indicating whether the survey respondent boarded a curbside bus. Model 2 replaces the curbside bus variable with variables indicating whether the survey respondent was a corporate curbside bus or Chinatown bus passenger. Models 3 through 5 add socio-demographic characteristics of survey respondents and two different measures of automobile access. Model 4 adds a variable indicating that the respondent could have easily or with little effort made the same trip by car. Model 5 includes a measure indicating that the household owns a car.

The model coefficients for the variables of interest are negative, significant, and consistent across the models. The results from model 5, suggest that, compared with legacy bus passengers, Chinatown bus passengers are 2.4 times more likely to state they are less likely to use Amtrak for intercity trips on 
the Northeast Corridor (2.4 is the inverse of the exponentiated model coefficient). Similarly, corporate curbside bus passengers are 2.3 times more likely to state they are less likely to use Amtrak for intercity trips on the Northeast Corridor than passengers boarding legacy bus companies.

Are travelers driving less after using curbside buses?

Curbside bus passengers are not abandoning the auto en masse to ride buses. Figure 5 shows the survey respondents' reported likelihood to drive since they began using curbside buses or legacy buses.

The main differences are that more corporate bus passengers stated they were much less likely or less likely to drive for future trips (50 percent), compared with Chinatown bus passengers (41 percent) and legacy bus passengers (33 percent), and fewer said their likelihood would not change. However, the ordered logit models do not find strong support for a difference between curbside bus passengers and legacy passengers in their likelihood to drive for future trips. In all but one of the model formulations, the results of the ordered logit analysis do not indicate any difference between curbside bus passengers and legacy passengers (Table 5). Chinatown bus passengers are not significant in any model, but corporate curbside bus passengers are significantly different from legacy bus passengers in model 4, which adds a variable indicating that the respondent could have made the current trip by car easily or with little trouble. In this model, the curbside bus variable is weakly significant $(\mathrm{p}<0.10)$ and negative, suggesting that curbside bus passengers might be less likely to drive for intercity trips on the Northeast Corridor, compared with legacy bus passengers, holding all else equal. But corporate curbside bus passengers are not significantly different in any other model, including model 5 , which replaces the auto access variable with a variable indicating auto ownership. Thus, I caution the reader against concluding that curbside bus use is associated with decreased driving for intercity trips.

\section{Why bus passengers are shifting to curbside buses}

Focus groups with curbside bus passengers supported the survey analysis, offered possible explanations for these findings, and suggest other possible trends in intercity travel behavior. The following is drawn largely from participants' discussions after I prompted them to discuss how their intercity travel behavior has changed over time.

Echoing the modeling results, the most common change participants described was transitioning from intercity trips on Amtrak to using curbside buses. Participants frequently cited the high cost of Amtrak tickets, compared with curbside bus fares, as the reason they transitioned from Amtrak rail to buses. One participant described his initial embarrassment that he could no longer afford Amtrak, but he came to realize that taking the Chinatown bus was becoming more common, so he was no longer ashamed of it:

\section{I love that high-speed train but my cash flow doesn't allow me [to ride it]. And so now I frequent the Chinese bus [SIC] all the time... I'm not reluctant to tell anyone about the Chinese bus... I don't care if I ran into, what's-his-name, vice president Biden. I would whisper to him, "Yo family, take the Chinese bus!"}

Very few focus group participants discussed curbside buses as a substitute for driving. This is surprising given that just over half of the respondents reported in the post-focus group questionnaire that they had traveled on the Northeast Corridor by car at least once during the 12 months preceding the focus group session. Participants who did talk about driving noted that they chose to drive when they had a lot of luggage or when it was faster. The general lack of discussion about changing driving habits supports the modeling results that traveling onboard curbside buses has little, if any, influence on the likelihood to drive for similar future trips. 
Table 5: Likelihood of using Amtrak.

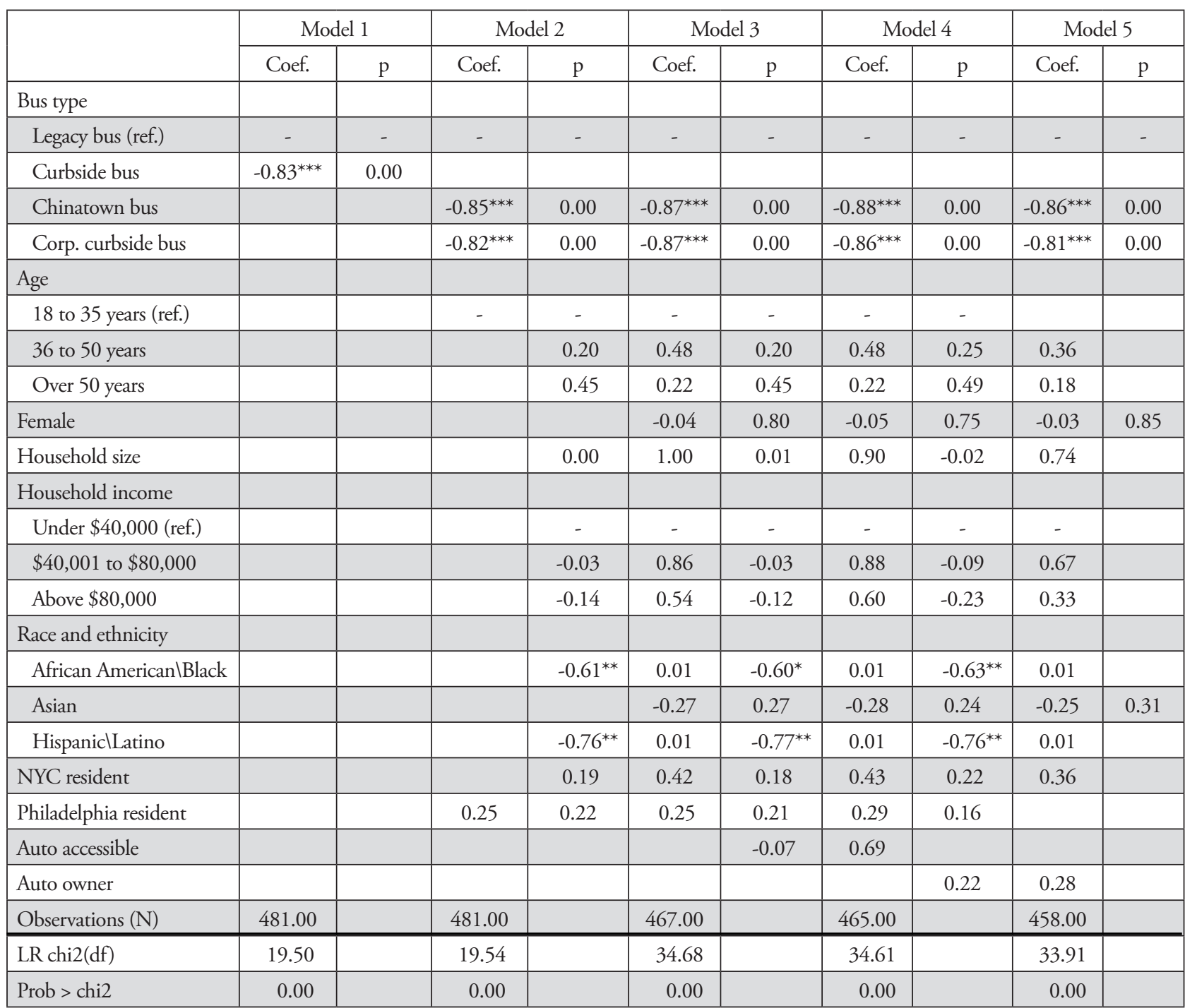

\begin{tabular}{|c|c|c|c|c|c|}
\hline \multirow[b]{2}{*}{$\begin{array}{l}\text { Chinatown } \\
\text { bus }\end{array}$} & $\begin{array}{c}\text { Much } \\
\text { Less likely }\end{array}$ & $\begin{array}{l}\text { Less } \\
\text { likely }\end{array}$ & $\begin{array}{l}\text { No } \\
\text { change }\end{array}$ & $\begin{array}{l}\text { More } \\
\text { likely }\end{array}$ & $\begin{array}{l}\text { Much } \\
\text { re likely }\end{array}$ \\
\hline & $20 \%$ & $21 \%$ & $39 \%$ & $12 \%$ & $8 \%$ \\
\hline Corp. bus & $20 \%$ & $30 \%$ & $33 \%$ & $13 \%$ & \\
\hline Legacy bus & $23 \%$ & $12 \%$ & $43 \%$ & $13 \%$ & $8 \%$ \\
\hline
\end{tabular}

Figure 5: Likelihood to drive since they started using curbside buses or legacy buses. 
Table 6: Likelihood of driving.

\begin{tabular}{|c|c|c|c|c|c|c|c|c|c|c|}
\hline & \multicolumn{2}{|c|}{ Model 1} & \multicolumn{2}{|c|}{ Model 2} & \multicolumn{2}{|c|}{ Model 3} & \multicolumn{2}{|c|}{ Model 4} & \multicolumn{2}{|c|}{ Model 5} \\
\hline & Coef. & $\mathrm{p}$ & Coef. & $\mathrm{p}$ & Coef. & $\mathrm{p}$ & Coef. & $\mathrm{p}$ & Coef. & $\mathrm{p}$ \\
\hline \multicolumn{11}{|l|}{ Bus type } \\
\hline Legacy bus (ref.) & - & - & - & - & - & - & - & - & - & - \\
\hline Curbside bus & -0.21 & 0.32 & & & & & & & & \\
\hline Chinatown bus & & & -0.11 & 0.67 & -0.10 & 0.69 & -0.10 & 0.70 & -0.06 & 0.82 \\
\hline Corp. curbside bus & & & -0.27 & 0.22 & -0.38 & 0.11 & $-0.42+$ & 0.07 & -0.35 & 0.13 \\
\hline \multicolumn{11}{|l|}{ Age } \\
\hline 18 to 35 years (ref.) & & & & & - & - & - & - & - & - \\
\hline 36 to 50 years & & & & & $-0.54+$ & 0.06 & $-0.60^{*}$ & 0.03 & $-0.52+$ & 0.07 \\
\hline Over 50 years & & & & & 0.17 & 0.65 & 0.15 & 0.70 & 0.17 & 0.66 \\
\hline Female & & & & & 0.18 & 0.29 & 0.13 & 0.44 & 0.15 & 0.41 \\
\hline Household size & & & & & 0.03 & 0.64 & 0.03 & 0.65 & -0.01 & 0.93 \\
\hline \multicolumn{11}{|l|}{ Household income } \\
\hline Under $\$ 40,000$ (ref.) & & & & & - & - & - & - & - & - \\
\hline$\$ 40,001$ to $\$ 80,000$ & & & & & 0.03 & 0.88 & -0.02 & 0.91 & -0.01 & 0.94 \\
\hline Above $\$ 80,000$ & & & & & $-0.64^{* *}$ & 0.01 & $-0.76^{* *}$ & 0.00 & $-0.74^{* *}$ & 0.00 \\
\hline \multicolumn{11}{|l|}{ Race and ethnicity } \\
\hline African Am. IBlack & & & & & $-0.45+$ & 0.07 & $-0.46+$ & 0.06 & $-0.52^{*}$ & 0.04 \\
\hline Asian & & & & & -0.32 & 0.18 & -0.25 & 0.31 & -0.30 & 0.22 \\
\hline HispaniclLatino & & & & & 0.40 & 0.19 & 0.46 & 0.13 & 0.34 & 0.27 \\
\hline NYC resident & & & & & -0.10 & 0.69 & -0.06 & 0.82 & 0.02 & 0.94 \\
\hline Philadelphia resident & & & & & -0.31 & 0.13 & -0.33 & 0.11 & -0.33 & 0.11 \\
\hline Auto accessible & & & & & & & $0.43^{*}$ & 0.02 & & \\
\hline Auto owner & & & & & & & & & $0.40+$ & 0.06 \\
\hline Observations $(\mathrm{N})$ & 454 & & 454 & & 441 & & 438 & & 433 & \\
\hline LR chi2(df) & 0.99 & & 1.72 & & 26.98 & & 33.21 & & 30.05 & \\
\hline Prob > chi 2 & 0.32 & & 0.42 & & $<0.01$ & & $<0.01$ & & $<0.05$ & \\
\hline
\end{tabular}

Note: $+\mathrm{p}<0.10,{ }^{*} \mathrm{p}<0.05,{ }^{* *} \mathrm{p}<0.01,{ }^{* * *} \mathrm{p}<0.001$

The focus groups' discussions also suggested other possible changes in travel behavior not examined in the survey. First, participants talked about switching from using legacy buses to curbside buses, stating they made this transition because they felt that curbside buses were cheaper, offered more frequent departures or a more convenient location, or they disliked bus terminals. Second, a number of participants described switching from Chinatown buses to corporate curbside buses because they felt that the corporate buses are more reliable, cleaner, safer, and offered more convenient locations.

I'm from New York. I've always taken the bus. Ever since I moved here [Philadelphia], I took the Greyhound. Then when I found out about the Chinatown bus, I took that. Then as soon as Greyhound became cheap because of the competition with the Chinatown bus, I took that. Then as soon as Megabus and those buses came around, I started taking those buses. 
Third, participants reported traveling more often on the Northeast Corridor since they started using curbside buses. Focus group participants attributed this to lowered cost of travel, as one noted: "I need to go to New York anyway, but I take more trips because it is so cheap."

Finally, many of the participants in the focus groups reported that their travel behavior had not changed at all as a result of curbside buses. These were participants who came of age or moved to the area after curbside buses were well established on the Northeast Corridor. For these travelers, curbside buses have always been an option. As one participant hyperbolically stated: "[The] Chinatown bus is the first thing I learned about when I came to the city [Philadelphia], which was five years ago."

\section{Discussion}

The intercity bus industry has experienced a remarkable transformation in the past 15 years. New companies have entered the market, ridership has steadily grown, and this increase has resulted in changes in the demographics of passengers and changes in intercity travel behavior. Intercity bus travel is no longer a mode of last resort, used only by the poor, young, very old, women, and minorities. Passengers boarding the new entrants to the marketplace, the Chinatown and corporate curbside buses, are quite different from those passengers boarding legacy buses. Those boarding corporate curbside buses are more likely white and affluent, and passengers boarding the Chinatown buses are more likely Asian, young, and male compared with those boarding other buses.

The new entrants to the market may be expanding intercity travel options, but they are not "greening" intercity travel. There is little evidence that after boarding a curbside bus, travelers are less likely to drive (see Table 6). I analyzed several statistical models, and only one of the model formulations found a significant relationship between taking a corporate curbside bus and a decreased propensity to drive. This statistically significant relationship could represent a weak relationship or statistical fluke, though further research is needed to untangle this relationship. However, after riding a curbside bus, survey respondents are much less likely to use Amtrak for future trips. According to focus group participants, they are switching form Amtrak to using curbside buses because curbside buses are much less expensive. Additionally, focus group participants noted that inexpensive curbside buses are allowing them to take more intercity trips. While I did not examine this type of behavior change in the survey, it is likely that decreases in travel costs and increases in intercity accessibility would lead to more travel.

Given these modal shifts, from rail to bus, the continued expansion of low-cost, high-frequency intercity bus services throughout the country may be a cause for concern for Amtrak and for future development of high-speed rail in the United States. And yet evidence from the Northeast Corridor suggests that expensive, high-quality rail service can coexist with curbside buses. Over the past 10 years, while curbside buses have been steadily gaining riders, Amtrak ridership has increased (Puentes et al. 2013). Where is the growth in Amtrak trips coming from? Perhaps intercity travel on the Northeast Corridor is increasing overall, and travel on all modes (rail, bus, driving, and flying) is rising. Or perhaps travelers who formerly used Amtrak are switching to bus, while other travelers who formerly flew or drove are now switching to Amtrak. This research highlighted the changes within the intercity bus market, and future research should examine the broader intercity trends within the Boston to Washington, DC, corridor.

\section{Acknowledgements}

The Transportation Coordinating Council and Federal Transit Administration (TCC/FTA) provided funding for this project through the research contract "The Impacts of Low-Cost Buses on the Transit Industry." Bob Noland, Dan Chatman, John Pucher, Evelyn Blumenberg, and Michael J. Smart all provided comments on various versions of this article. Andrew Zitcer and Haiyan Zhang assisted with 
the focus group recruitment, moderation, and translation. Xiao He, Steve Hurst, Lewis Thorwaldson, and Devin Reitsma all assisted with the survey collection.

\section{Notes}

${ }^{1}$ In this article, I use the term "Chinatown bus" to describe a set of independent bus companies largely staging their operations in Chinese ethnic enclaves. Many, but not all, of these bus companies share common characteristics. My use of the term, however inaccurate, mirrors the way many participants in my focus groups used the term to describe the collection of independent bus companies that operate in Chinatowns and are distinct from other types of bus companies (Klein and Zitcer 2012).

${ }^{2}$ I did not ask about respondents' likelihood to travel by plane. During the focus groups with intercity bus passengers, only one of the 39 participants talked about traveling by plane between cities on the Northeast Corridor. The small number of respondents who traveled by plane is supported by Schwieterman and Fischer (2012) who found that only 6 percent of curbside bus passengers on the East Coast would have flown had their bus not been an option for their trip.

${ }^{3}$ In the survey, I also asked respondents about their likelihood to use commuter rail for travel between Philadelphia and New York (via Southeastern Pennsylvania Transportation Authority and New Jersey Transit). I do not include that analysis here because intercity buses compete with commuter rail in very few locales.

${ }^{4}$ The model results remained consistent when I tested alternative model formulations. I used different models (ordered probit instead of logic), simplified the number of categories in the dependent variable (collapsing the outcomes to two or three outcomes, using a logit and probit model for the former tests), and when I included or excluded specific variables and altering the construction of the independent variables. In all cases, the model results were similar regardless of which measure I used.

${ }^{5}$ In the model, I coded the race categories as dummy variables and the reference category is not of that race. Thus for the African-American category, the reference category is not African-American.

\section{References}

Arino, L. 2014. Long-Distance Bus Lines Are Overwhelming Chinatown, Residents Say [Online]. New York, NY: DNAinfo.com. http://www.dnainfo.com/new-york/20140612/lower-east-side/long-distance-bus-lines-are-overwhelming-chinatown-residents-say.

Berechman, J. 1993. Public Transit Economics and Deregulation Policy. Amsterdam: North-Holland.

BoltBus. 2013. BoltBus website. www.boltbus.com.

Bricka, S. 2001. Variations in long-distance travel. Transportation Research Circular E-C026: 10.

Fischer, L. A., and J. P. Schwieterman. 2011. The decline and recovery of intercity bus service in the United States: A comeback for an environmentally friendly transportation mode? Environmental Practice 13: 7-15.

Greyhound Bus Lines. 2007. Northeast corridor study (unpublished).

Klein, N. 2009. Emergent curbside intercity bus industry: Chinatown and beyond. Transportation Research Record 2111: 83-89.

Klein, N. 2014. Curbside buses and the transformation of the intercity bus industry. Ph.D. dissertation. Rutgers, New Brunswick, NJ.

Klein, N., and A. Zitcer. 2012. Everything but the chickens: Cultural authenticity onboard the Chinatown bus. Urban Geography 33: 46-63.

Megabus. 2013. Megabus website. us.megabus.com.

Meyer, J. R., C. V. Oster, J. A. Gomez-Ibanez, and M. Clippinger. 1987. The other modes: Bus, rail and auto. In J. R. Meyer and C. V. Oster. (eds.), Deregulation and the Future of Intercity Passenger Travel. Cambridge, MA: MIT Press.

Puentes, R., A. Tomer, and J. Kane. 2013. A New Alignment: Strengthening America's Commitment to 
Passenger Rail. Washington, DC: The Brookings Institution.

Schwieterman, J. and L. Fischer. 2012. Competition from the curb. Transportation Research Record 2277: 49-56.

Schwieterman, J. P., B. Antolin, P. Largent, and M. Schulz. 2013. The Motor Coach Metamorphosis: 2012 Year-in-Review of Intercity Bus Service in the United States. Chicago: Chaddick Institute for Metropolitan Development, DePaul University.

Schwieterman, J. P., L Fischer, C. Ghoshal, P. Largent, N. Netzel, and M. Schulz. 2011. The Intercity Bus Rolls to Record Expansion: 2011 Update on Scheduled Motor Coach Service in the United States. Chicago: Chaddick Institute for Metropolitan Development, DePaul University.

Schwieterman, J. P., L. Fischer, S. Smith, and C. Towles. 2007. The Return of the Intercity Bus: The Decline and Recovery of Scheduled Service to American Cities, 1960-2007. Chicago: School of Public Service Policy Study, DePaul University.

U.S. Department of Transportation. 1998. Transportation Statistics Annual Report 1998. Washington, DC: USDOT.

U.S. Department of Transportation. 2013. FMCSA shuts down Fung Wah bus transportation [Online]. Washington, DC: Federal Motor Carrier Safety Administration. http://www.fmcsa.dot.gov/ about/news/news-releases/2013/FMCSA-Shuts-Down-Fung-Wah.aspx.

Valenzuela, A. J., L. Schweitzer, and A. Robles. 2005. Camionetas: Informal travel among immigrants. Transportation Research A 39: 895-911.

Walsh, M. 2000. Making Connections: The Long-Distance Bus Industry in the USA. Aldershot, UK: Ashgate.

White, P., and D. Robbins. 2012. Long-term development of express coach services in Britain. Research in Transportation Economics 36: 30-38. 